\title{
Whooping Crane Winter Count, 1962-63
}

by Fred G. Bard, Saskatchewan Museum of Natural History

\section{$1938 \quad 40 \quad 42 \quad 44 \quad 46 \quad 48 \quad 50 \quad 52 \quad 54 \quad 56 \quad 58 \quad 60 \quad 62$}

40

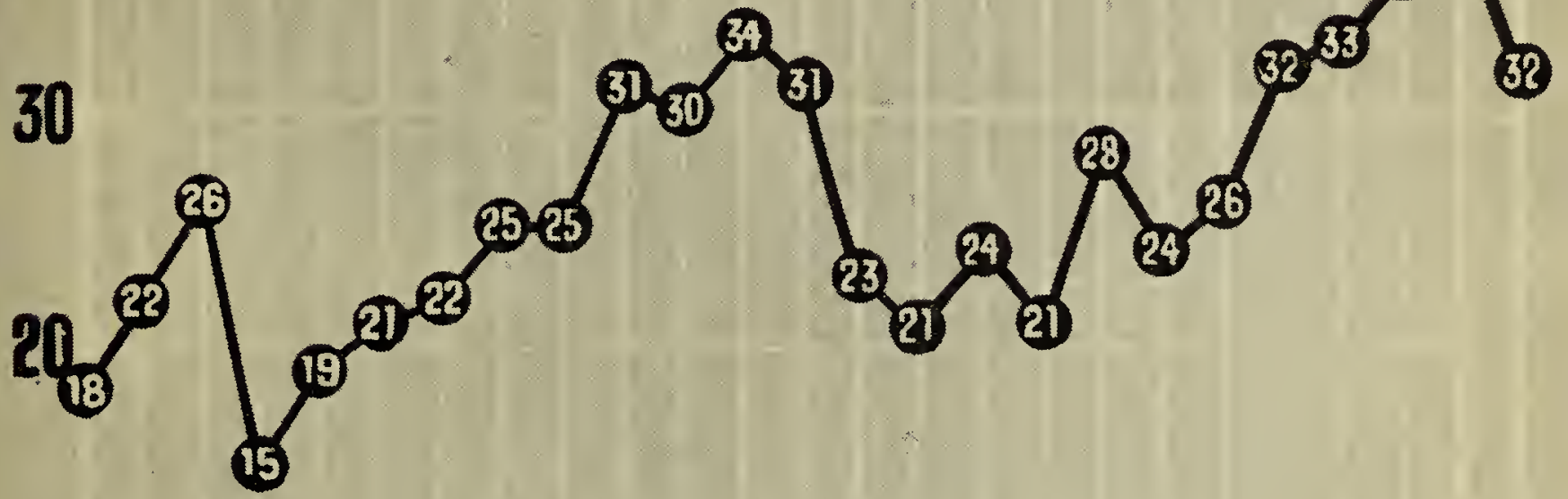

10

0

Fig. 1. Wintering population of Whooping Cranes at Aransas, 1938-1962.

The news of the loss of six Whooping Cranes that failed to arrive in the Aransas National Wildlife Refuge is disconcerting. It may never be known what happened to these birds. One report attributed the losses to American hunters shooting Sandhill Cranes. I understand, however, that areas opened to hunting Sandhill Cranes were not frequented by Whooping Cranes. This year's experience indicates how little we know about crane losses and how difficult it is to prevent them.

From statistics gathered (we stand to be corrected) we submit two charts. One covers the wintering population in the Aransas Refuge from 1938 to 1962 (fig. 1); the other shows the six years of greatest losses since 1940 (fig. 2). Many of us feel that the captive birds in New, Orleans offer the opportunity for building up the Whooping Crane population, but the birds and George Douglas need more than good wishes.

The Whooping Cranes wintering at Aransas are an inspiring sight, how can these birds succeed in maintaining or increasing their numbers on their own in the face of changing land use, the draining of wetlands, development pressures, increased hunting and the expanding use of chemicals? These are dangers that threaten the cranes all the way from Wood Buffalo National Park to the Aransas National Wildlife Refugea distance of about 2,500 miles.

The Whooping Crane is not just another bird-it has become a symbol illustrating how little we really care about our wildlife inheritance. Through our indifference we can easily be responsible for the loss of another species. We should accept the challenge and get together to help avert this tragedy.

\section{LOSSES. WORST YEARS}

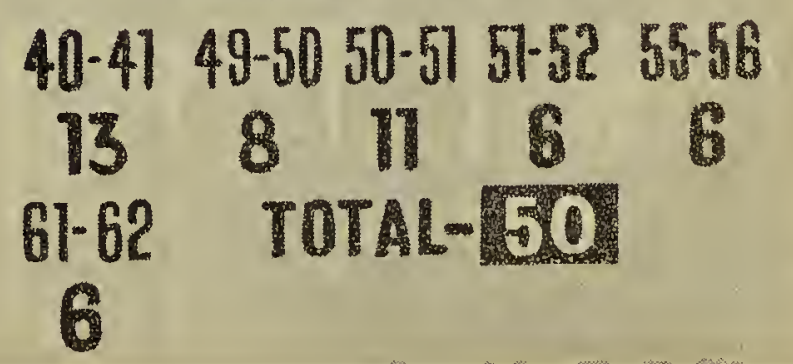

Fig. 2. Yeors of heoviest losses, 1940-1962. 